\title{
A window into pain
}

$\mathrm{H}$ er hair was a colour of red not normally seen in 78 -year-olds. The gray and white roots betrayed her increasing length of stay on the ward. She had come in because of an exacerbation of her congestive heart failure - now stable; atrial fibrillation - now stable; and ongoing back pain - stable, but ever more troubling. Acetaminophen, NSAIDS, tricyclics, opioids: nothing touched this pain.

Miriam Herschel was now lying in the bed and I was sitting at the bedside. She was telling me that she had been in pain since she was a young woman and nothing had really got rid of it. She had been able to function - worked, married, had children, kept the house for years. But now, as she and her husband aged, the pain seemed stronger and affected her much more.

The pain itself was elusive: tests failed to reveal a prolapsed disc, compression fracture or spinal stenosis. She had degenerative changes in her lumbar spine as anyone who is almost 80 would, but it did not explain the disabling pain she was experiencing.

The effect of diuresis and rhythm regulation had peaked and it seemed now she was succumbing to the iatrogenic cascade and polypharmacy.

Not learning much from the presenting complaint I began to ask about her history. She was born in Germany in 1925. Her accent confirmed this. Her name then was Gershon - and she lived in a suburb of Berlin. She had an older brother - three years her senior. They grew up together with their extended family in a Jewish neighbourhood.

"What happened to you during the war?" I asked.

"I was sent to England. I stayed there, met and married my husband and then we came to Canada."

Simply said, but the gap was ominous.

"What about your family?"

"Did you ever hear of the Kinder-

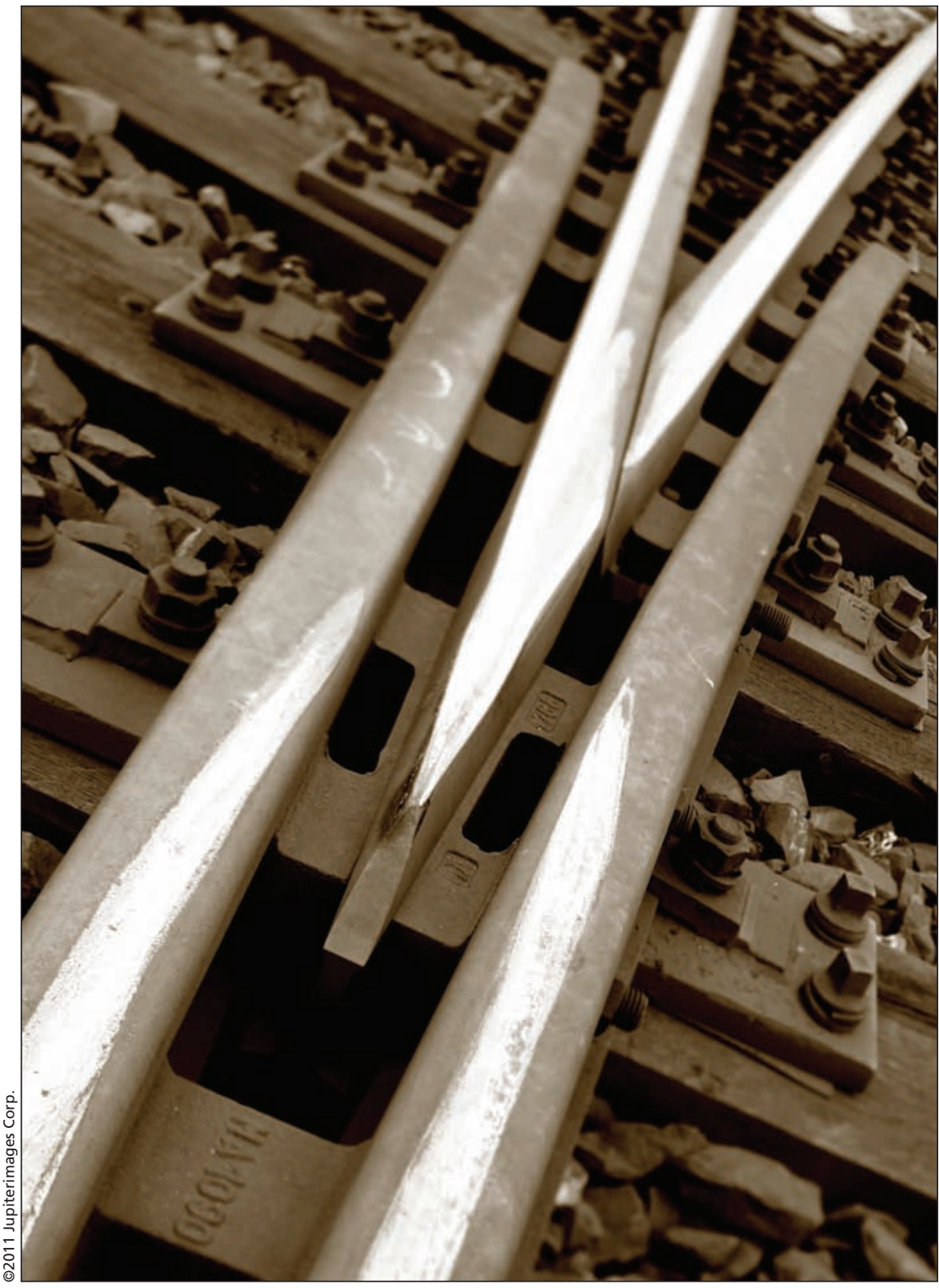

transport?" she asked. "England agreed to take Jewish children under the age of 17. It was after Kristallnacht. Our family's shoe store had been destroyed and my uncle had been taken away by the Nazis. My mother and father insisted that I go. I really wanted my brother to go too — but he was 17 and was too old."
"So you were sent on your own and separated from your family? Did you see them again?"

Her eyes widened and her voice tensed.

"My father and mother and brother came to the station to send me away. There were mostly smaller children on 
the train car with me. I ... I really did not want to go but in a way I was relieved. I remember seeing them through the train window - smiling and crying. Mostly I saw my father smiling and waving, pretending he was sending me on a holiday. My mother ... she tried smiling but her arm would not wave. My brother ... he stood in front, like a shield, yes ... he was proud he was old enough to stay and that I had to go because I was younger."

"I never saw them again. They were taken to a camp - I do not know which. I am the only one to survive."

"That must have been awful for you!" I said. "How terrible, none of your family survived."

"Yes, that was hard, but ..."

"Mm ... hmm?"

"I was so bad. Those little children at the window, they did not know it would be their last look, their parent's last look."

She paused and I waited. What could be worse?

Her anguish surged.

"As the train left, I pushed them out of the way - out of the way! so I could see my parents and my brother. I knew, but... I pushed them out of the way!" Her chest rose and fell with grief.

One selfish but understandable action, I thought. Rather than focus on her own grief of being sent away she chose to focus on her seemingly thoughtless action toward the other children.

"You are very hard on yourself, I said. "It sounds as though you feel guilty for surviving."

"Yes, yes I do. I don't understand why I was the only one. Why me? I should have been there with my family ..."

We stayed together in silence.

"Do you think your back pain is in some way related to what happened?" I asked. "Could it be a reminder that you are the only survivor? That you bear the pain of being the only one left and knowing their suffering?"

"I suppose. I've had it since I was an adult. I do carry pain."

"Perhaps we cannot get rid of it. Maybe it is the burden you carry as the survivor. Maybe knowing this, it will hurt you less and will not worry you as much."
We visited several times after that. The team was no longer expecting to eliminate this pain and so fewer drugs meant fewer side effects. She began to get up and move around. She seemed lighter or so it seemed to me. She was even able to join in singing Christmas carols and requested her favourite "White Christmas." Going home soon followed.

Sharing that anguish had - I hoped - helped her. It has stayed with me, the power of a child's understanding and memory. No matter how much evil surrounded her, it was her own minor lapse of civility that scarred the deepest. Freedom may come from holding that moment up again for the mature heart to appraise.

\section{Romayne Gallagher MD}

Physician program director Palliative Care Program

Providence Health Care Vancouver, BC

Editor's note: The patient gave consent for her story to be told. Her name has been changed. 